\title{
VOZES DO ARROIO PAMPA E PERI (NOVO HAMBURGO/RS): A EDUCOMUNICAÇÃO COMO PROPOSTA PEDAGÓGICA PARA A EDUCAÇÃO AMBIENTAL ${ }^{1}$
}

Adriana Backes ${ }^{2}$

Caio Floriano dos Santos ${ }^{3}$

Resumo: $O$ presente artigo apresenta o projeto de Educação Ambiental realizado na Escola Municipal de Ensino Fundamental Presidente Deodoro da Fonseca, com o objetivo de retratar as problemáticas socioambientais (entre elas, a poluição e os alagamentos) vividas pela comunidade escolar, que mora no entorno dos arroios Peri e Pampa, no município de Novo Hamburgo, dando voz aos diferentes atores sociais envolvidos nessa realidade. Como metodologia, utilizamos a Educomunicação, a fim de elaborar um documentário que foi denominado "Vozes do Arroio Pampa e Peri", produzido pelos alunos e exibido à comunidade, possibilitando o reconhecimento e a problematização crítica da realidade encontrada, ampliando e complexificando o debate, que inclui questões políticas, sociais e de justiça ambiental.

Palavras-chave: Educação Ambiental; Educomunicação; Justiça Ambiental; Arroios.

\footnotetext{
1 Projeto de ação desenvolvido a partir do Curso de Especialização em Educação Ambiental oferecido pela Universidade Aberta do Brasil e Universidade Federal do Rio Grande - FURG.

2 Pedagoga (FEEVALE). Especialista em Educação Ambiental (UAB/FURG).

E-mail: adrianabackesmacedo@gmail.com

3 Oceanógrafo (UNIVALI). Mestre em Planejamento Territorial e Desenvolvimento Socioambiental (UDESC). Doutorando no Programa de Pós-Graduação em Educação Ambiental (PPGEA) da Universidade Federal do Rio Grande (FURG). Bolsista FAPERGS/CAPES. Docente no curso de especialização em Educação em Educação Ambiental - UAB/FURG. E-mail: santoscaiof@gmail.com
}

Revbea, São Paulo, V. 11, № 1: 335-354, 2016.

revista brasileira educação ambiental 


\section{Introdução}

O presente artigo apresenta os resultados do Projeto de Ação de Educação Ambiental - EA realizado na Escola Municipal de Ensino Fundamental Presidente Deodoro da Fonseca, localizada entre os arroios Pampa e Peri, no bairro Canudos, município de Novo Hamburgo. Esse município atualmente possui 238.940 habitantes concentrados em uma área de $223,821 \mathrm{~km}^{2}$ e está localizado na região metropolitana de Porto Alegre, estado do Rio Grande do Sul (IBGE, 2010) ${ }^{4}$.

Atuando como professora há dez anos nessa escola, tenho acompanhado a realidade enfrentada e as situações vividas pela comunidade escolar, que convive com a poluição desses arroios e com o risco dos alagamentos, inundações e enchentes que ocasionam perdas e causam traumas. As enchentes ${ }^{5}$, na nossa percepção, têm-se tornado cada vez mais constantes e graves. Através da pesquisa sócio antropológica ${ }^{6}$ realizada na comunidade e por ocasião dos alagamentos ocorridos, os pais manifestaram o desejo de que a escola trabalhe a questão da poluição nos rios e das inundações. Paralelo a isso, a comunidade também manifestou sua insatisfação, fechando ruas e pedindo solução para as autoridades em relação a essa questão, demonstrando a existência de um conflito explícito.

A partir disso, decidimos pela realização de um projeto de Educomunicação com alunos do $3^{\circ}$ ano do Ensino Fundamental. Dessa forma, visamos à construção de um projeto que dê possibilidades aos atores sociais envolvidos de falarem sobre seus saberes, suas vivências, opiniões, expectativas, sentimentos e, principalmente, que possam expressar a relação com os arroios que passam pela comunidade. Para tanto, outros setores da sociedade foram convidados a participarem da conversa, visando à troca de saberes, vivências e responsabilidades dos atores sociais implicados nessa realidade socioambiental, em que se encontram deflagrados conflitos e injustiça ambiental ${ }^{7}$.

Precisamos perceber as consequências negativas (ambientais e sociais), para que possamos buscar formas de mudar essa realidade. Para tanto, buscamos desenvolver o projeto de Educação Ambiental cuja proposta fosse a de caminhar lado a lado da comunidade, com o intuito de somar forças em defesa de seus interesses e buscar incluir reflexões e debates relativos aos temas de conflitos sociais e justiça ambiental (SANTOS et al., 2013).

${ }^{4}$ Dados do município de Novo Hamburgo: http://cidades.ibge.gov.br/xtras/perfil. php?lang=\&codmun $=431340$.

${ }^{5}$ Santos (2010) e Santos et al. (2014) utilizam o termo enchente para descrever inundações por ser a forma como a comunidade, a comunidade escolar e os alunos se referem ao fenômeno.

${ }^{6}$ Pesquisa realizada nas escolas da rede municipal de ensino conforme orientações da SMED de Novo Hamburgo, no mês de março de 2014. A denominação sócio antropológica foi utilizada na pesquisa e que mantemos como no original.

${ }^{7}$ Usamos a definição de Injustiça Ambiental cunhada por Acselrad et al. (2009).Em que "para designar esse fenômeno de imposição desproporcional dos riscos ambientais às populações menos dotadas de recursos financeiros, políticos e informacionais, tem sido consagrado o termo injustiça ambiental" (ACSELRAD; MELLO; BEZERRA, 2009, p. 9).

Revbea, São Paulo, V. 11, № 1: 335-354, 2016. 
O município de Novo Hamburgo está inserido na Bacia Hidrográfica do Rio dos Sinos que nasce em Caraá (numa altitude de setecentos metros), estendendo-se até o Delta do Jacuí ${ }^{8}$. O município é dividido em quatro microbacias, formadas pelos arroios Pampa, Cerquinha, Luiz Rau e Gauchinho. Além desses, vários são os arroios que deságuam na região da várzea do Rio dos Sinos, tanto na margem norte do rio quanto na sul (Figura1). Os arroios da margem sul estão todos localizados no bairro de Lomba Grande, enquanto que, na margem norte, chegam as águas dos arroios cujas nascentes situam-se nos morros de Novo Hamburgo.

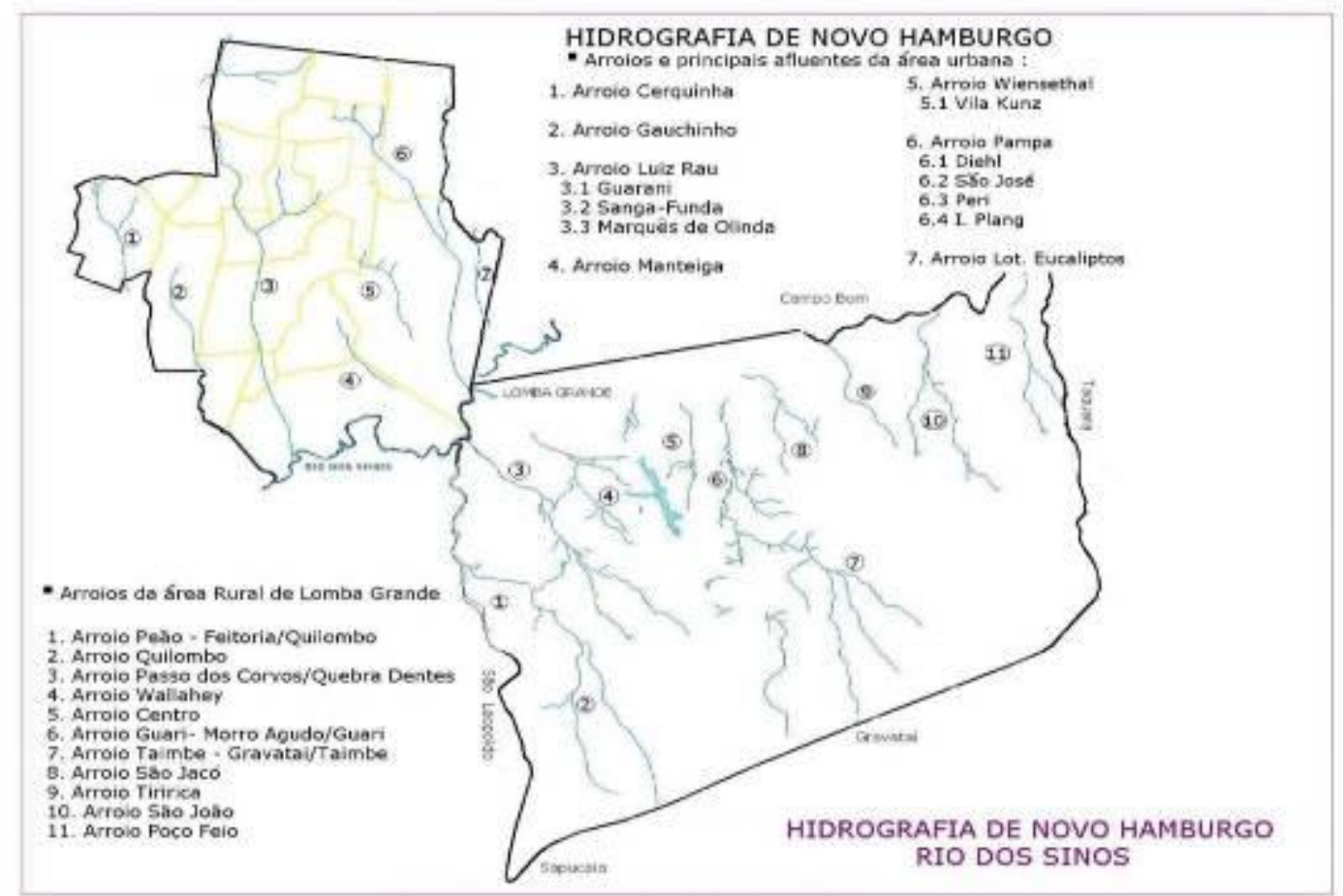

Figura 1: Mapa da Bacia Hidrográfica do Rio dos Sinos.

Fonte: http://www.comusa.rs.gov.br/index.php/meioAmbiente/pesquisa

Os arroios que deságuam no Rio dos $\operatorname{Sinos}^{9}$, fornecedor da água para o abastecimento do município, sofrem com vários impactos ambientais negativos,

\footnotetext{
${ }^{8}$ Informações disponíveis no site: http://novohamburgo.org/site/nossa-cidade/dados-gerais/

${ }^{9} \mathrm{O}$ Rio dos Sinos é apontado como sendo o quarto mais poluído do Brasil por alguns sites, entre os quais, http://www.ecodesenvolvimento.org/posts/2012/marco/dados-do-ids-destacam-os-10-rios-mais-poluidosdo e http://g1.globo.com/rs/rio-grande-do-sul/noticia/2015/04/nivel-de-oxigenio-se-aproxima-de-zero-nasaguas-do-rio-dos-sinos.html, que referenciam como fonte os dados do IDS 2010 (Indicadores de Desenvolvimento Sustentável), do IBGE. Porém, no site do IBGE(http://www.ibge.gov.br/home/geociencias/recursosnaturais/ids/ids2010.pdf), não encontramos essa referência direta, mas encontramos descrito "que o rio dos Sinos é considerado o mais poluído da região de Porto Alegre, pois possui grande parque industrial, com destaque para a indústria coureiro-calçadista", além de diversas tabelas, demonstrando a qualidade das águas doces.
} 
dos quais podemos citar: esgoto, assoreamento, lixo jogado diretamente nas suas águas e margens e outros, trazendo sérias consequências para a sociedade, distribuídas de forma desigual entre sua população.

Poderíamos trazer aqui como impacto ambiental, sob um olhar simplista, a ocupação de áreas de preservação permanente, pois muitos dos moradores que ali se instalaram apenas o fizeram por não terem outra opção de moradia, em virtude de questões econômicas e sociais, como relata um pai, no debate realizado na escola: "ninguém mora perto dos arroios porque quer!", o que, segundo nosso entendimento, configura uma questão de desigualdade ambiental. Essa é a situação enfrentada por muitos dos integrantes da comunidade escolar, uma vez que moram às margens ou nas proximidades dos arroios Pampa e Peri (Figura 2).

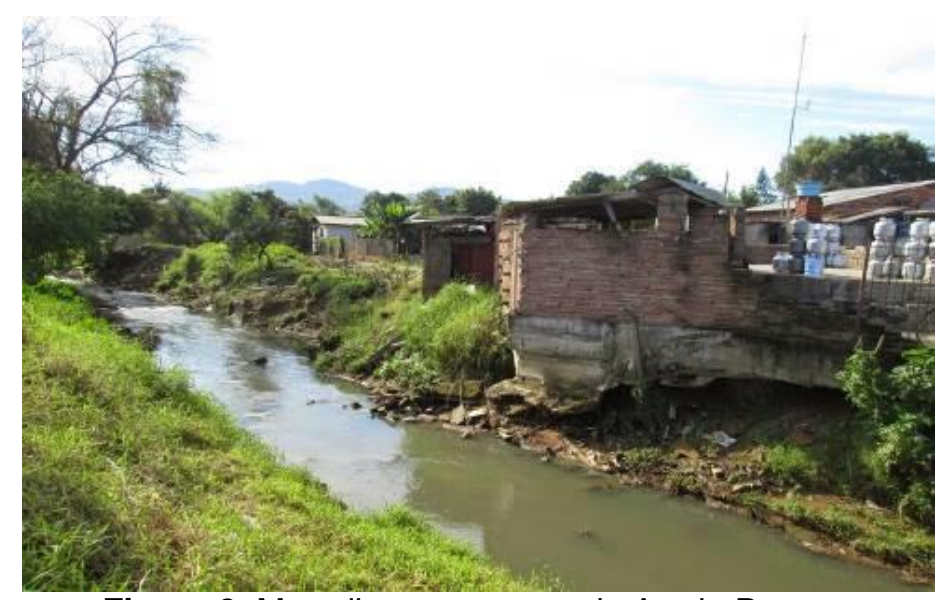

Figura 2: Moradias no entorno do Arroio Pampa.

Fonte: Alunos participantes do projeto.

Eis a realidade que procuramos retratar e debater, com a realização do documentário "Vozes do Arroio Pampa e Peri", projeto pensado, planejado e executado por alunos do $3^{\text {o }}$ ano do Ensino Fundamental, possibilitando um registro do momento vivido pela comunidade e abrindo espaço para um diálogo problematizador acerca da realidade. Indo ao encontro dos ensinamentos de Paulo Freire que diz que:

Através do diálogo crítico sobre um texto ou um momento da sociedade, tentamos penetrá-lo, desvendá-lo, ver as razões pelas quais ele é como é, o contexto político e histórico em que se insere. Isto é para mim um ato de conhecimento e não uma mera transferência de conhecimento (FREIRE, 1986, p. 24). por outro lado, as responsabilidades e as ações colocadas em práticas ou que ainda devem ser contempladas por outros setores da sociedade para a Revbea, São Paulo, V. 11, № 1: 335-354, 2016. 
modificação da realidade em questão. Ao mesmo tempo, percebemos que devemos nos desafiar a ampliar nossa reflexão, debates e atuações, visando à transformação da estrutura social, política e econômica existente, que deverá ser repensada e modificada para transpormos a realidade catastrófica que tem trazido prejuízos econômicos, ambientais e sociais para as comunidades que vivem no entorno de arroios (THIELE, 2004).

\section{A EA e a Educomunicação: legislação, concepções e opções}

No ano de 2012, ocorreu a I Conferência Municipal de Educação de Novo Hamburgo, cujo tema foi "A construção solidária de um projeto estratégico de educação para Novo Hamburgo". Nessa conferência, se discutiu a educação no município a partir de eixos temáticos, como, por exemplo, o Eixo 6, que tratava da Educação Ambiental e da Sustentabilidade. $\mathrm{Na}$ proposição para a construção do referido eixo, fica registrado que:

Os principais documentos que sustentam a Educação Ambiental são o Artigo 225 da Constituição Federal Brasileira de 1998 e a Lei Federal n 9.795, de 27/04/99 que institui a Política Nacional de Educação Ambiental e dá outras providências sobre a condução dos processos e meios para sua aplicação. Esta Lei Federal $n^{\circ} 9.795$ destaca no artigo 4응 os princípios básicos da educação ambiental e nos artigos $11^{\circ}$ e $12^{\circ}$, aspectos do currículo da educação ambiental e a garantia do ensino formal e informal, tanto na rede pública como privada. Estes princípios e enunciados orientam a proposta de Educação Ambiental da Rede Municipal de Novo Hamburgo (I Conferência Municipal de Educação, 2012).

A EA no município regulamentou-se em conformidade com as leis vigentes em nosso país. A partir da definição de tais diretrizes, o debate avançou até chegar ao entendimento que se tem de Educação Ambiental em nossa rede de ensino:

A construção de responsabilidades socioambientais entre escola e comunidade. Abrange a sustentabilidade, a segurança alimentar, os ecossistemas, a economia local, as espécies, a interação humana, a energia e as tecnologias sustentáveis. É um processo contínuo de aprendizagem interdisciplinar em um currículo que valoriza os aspectos locais, regionais e globais (I Conferência Municipal de Educação, 2012, p.11).

Tendo em vista a legislação aqui referenciada e diante do contexto ambiental que estamos inseridos $e$ ao qual nos sentimos 
pertencentes,procuramos atuar de forma a problematizar e compreender esse lugar (COUSIN, 2010). Com isso, busca-se romper com a concepção construída historicamente pela sociedade industrial capitalista moderna e ampliar o nosso olhar frente aos conflitos ambientais vivenciados em nossa comunidade, lidando, assim, com as questões de injustiça e justiça ambiental, já que os conflitos:

[...] evidenciam que há uma configuração desigual - que chamamos de injustiça ambiental [...] que não devem ser vistos como um risco ou problema a ser mediado, mas [...] como uma primeira evidência da configuração desigual da sociedade e uma possibilidade de ruptura com essa realidade e sua posterior superação" (SANTOS et al., 2013, p.201).

Enfatizamos que a "justiça ambiental" consta no texto das Diretrizes Curriculares Nacionais para a EA, documento elaborado em 2012. Conforme evidencia o Art. 3:

A Educação Ambiental visa à construção de conhecimentos, ao desenvolvimento das habilidades, atitudes e valores sociais, ao cuidado e com a comunidade de vida, a justiça e a equidade socioambiental, e a proteção do meio ambiente natural e construído (BRASIL, 2012).

Ainda,a questão da justiça ambiental se encontra destacado no Art. 17, enfatizando que a mesma deve ser fomentada pelo planejamento e pelo currículo escolar, propondo que se efetue uma:

e) reflexão sobre as desigualdades socioeconômicas e seus impactos ambientais que recaem principalmente sobre grupos vulneráveis, visando à conquista da justiça ambiental (Ibidem, 2012).

Conscientes dessa configuração desigual da sociedade, propomo-nos a exercer uma educação ambiental impregnada de cidadania, o que demanda "a emergência de novos saberes para apreender processos sociais que se complexifiquem e riscos ambientais que se intensificam" (JACOBI, 2003, p.6). $\mathrm{E}$ com tal intuito, nos desafiamos a promover, conforme nos propõem Santos et al. (2013), "uma educação ambiental que se coloque lado a lado dos mais fracos e desorganizados visando aumentar-lhes as forças na defesa de seus interesses". 
Coerentemente com essa abordagem emancipatória, Loureiro (2007) coloca como possibilidade a construção de alguns caminhos. Entre eles, o autor propõe a construção de canais de participação e diálogo, a consolidação da relação escola-comunidade e um diálogo complexo com o mundo. Nesse sentido, Trajber (2005) reforça que, para isso:

[...] é preciso ir além da fala e da escrita, experimentando as linguagens da imagem, do som e do movimento em suas integrações com o uso das novas tecnologias da informação e da comunicação, principalmente a Internet (TRAJBER, 2005, p. 153)

Em face da utopia da emancipação e das propostas de construção de canais de participação e diálogo, nos propomos à realização de um projeto de Educomunicação Socioambiental. Essa comunicação:

[...] Refere-se ao conjunto de ações e valores que correspondem à dimensão pedagógica dos processos comunicativos ambientais, marcados pelo dialogismo, pela participação e pelo trabalho coletivo. A indissociabilidade entre questões sociais e ambientais no fazer-pensar dos atos educativos e comunicativos é ressaltada pelo termo socioambiental [sic]. A dimensão pedagógica, nesse caso em particular, tem foco no 'como' se gera os saberes e 'o que' se aprende na produção cultural, na interação social e com a natureza (COSTA, 2008, p.10).

Ainda, conforme Costa (2008) a Educomunicação Socioambiental tem como princípios norteadores uma série de comprometimentos, a saber: compromisso com o diálogo permanente e continuado, com a interatividade e a produção, com a transversalidade, com o encontro/diálogo de saberes, com a proteção e a valorização do conhecimento tradicional e popular, com a democratização da comunicação e com a acessibilidade à informação socioambiental, o direito à comunicação e à não discriminação e o respeito à individualidade e à diversidade humana. A Educomunicação tem como marco legal:

A Lei Federal 9.795, de 1999, que dispõe sobre a Educação Ambiental, instituiu a Política Nacional de Educação Ambiental. O Órgão Gestor desta política, por ela estabelecido (Ministério do Meio Ambiente e Ministério da Educação) recria, em 2003, o Programa Nacional de Educação Ambiental (ProNEA). O ProNEA adota, então, como uma de suas linhas de ação, a "Comunicação para a Educação Ambiental" e a descreve como: "produzir, gerir e disponibilizar, de forma interativa e dinâmica, as informações relativas à Educação Ambiental (COSTA, 2008, p.4) 
A democratização e o acesso à informação relativa às questões socioambientais pertinentes à comunidade, a qual o sujeito pertence, trata-se, também, de uma questão de justiça ambiental, uma vez que passa a ter assegurado amplo acesso às informações relevantes:

[...] sobre o uso dos recursos ambientais e a destinação de rejeitos e localização de fontes de riscos ambientais, bem como processos democráticos e participativos na definição de políticas, planos, programas e projetos que thes dizem respeito (ACSELRAD, 2005, p. 224)

A temática ambiental ganhou evidência na mídia a partir da Rio 92 (Conferência das Nações Unidas sobre Meio Ambiente e Desenvolvimento), realizada na cidade do Rio de Janeiro. A partir desse momento, abre-se espaço para o discurso ambiental devido, em grande parte, à aprovação da Lei 9.795/99, que institui a Política Nacional de Educação Ambiental (PNEA). O artigo $3^{\circ}$ incumbe a mídia de ser uma das responsáveis pela Educação Ambiental e, no artigo $13^{\circ}$ da mesma lei, o Poder Público fica responsabilizado por incentivar a difusão de informações acerca de temas relacionados ao meio ambiente por intermédio dos meios de comunicação de massa, em espaços nobres. No entanto, observa-se outra realidade:

Na prática, o que ocorreu após a aprovação da PNEA é que, de fato e também de direito, a mídia nacional incorporou o discurso ambiental em sua programação, mas principalmente nos horários de menor audiência. Tal trato demonstra a importância efetiva que a mídia confere à temática. Além disso, deu ao discurso ambiental a feição mais disforme possível, em que todos aparecem como culpados pelos "problemas" ambientais, enquanto, em contrapartida, atribui-se a cada um a solução (ARAÚJO, 2013, p. 2)

É um imenso desafio defender um posicionamento frente ao poder midiático, pois este legitima a ideologia dominante e acompanha a legislação que se propõe a educar ambientalmente, de forma dita neutra e ecologicamente correta, porém, mantém um discurso que posiciona a natureza como um recurso a serviço do ser humano. Precisamos entender que "assim como fazer educação, fazer comunicação, nesse caso, é mais que um ato profissional. É, sim, um direito e uma ação emancipatória de todo cidadão" (COSTA, 2008, p. 23).

Nesse sentido, a Educomunicação pode ser vista como uma possibilidade de fazer frente a mídias que não dialogam de maneira problematizada a respeito da crise civilizatória e ambiental pela qual a nossa 
sociedade está passando, e não se detêm a um debate fomentador de questões relativas às causas dessa crise.

\section{A Educomunicação como metodologia da EA transformadora}

O projeto de Educomunicação foi efetivado com os alunos do $3^{\circ}$ ano do Ensino Fundamental da nossa escola, durante as aulas de "Projeto de Ciências Naturais e Educação Ambiental", pelas quais sou responsável, ocorridas semanalmente com a participação da professora titular da turma, que trabalhou de forma interdisciplinar no seu dia a dia de sala de aula, ampliando e enriquecendo o projeto, além da colaboração nas saídas a campo para entrevistas, fotos e filmagens. $O$ documentário realizado pelos alunos no $2^{\circ}$ semestre de 2015 deu voz a nossa comunidade. Os entrevistados colocaram seus pontos de vista em relação aos arroios, sentimentos diante dos alagamentos, lembranças, conflitos e o que esperam das autoridades e das comunidades. Também foram realizadas entrevistas com a Companhia Municipal de Saneamento (COMUSA) e com o Comitê de Gerenciamento da Bacia Hidrográfica do Rio dos Sinos (COMITESINOS), respondendo sobre suas competências, o que têm feito e o que pretendem fazer. Registramos que foram feitas solicitações de entrevista ao prefeito do município, por telefone e em encontro com o mesmo, durante a Mostra de Trabalhos Científicos do Município, e ficamos no aguardo do agendamento da data que acabou não se efetivando.

Iniciamos com a roda de conversas. Primeiramente com a fotógrafa, que após a conversa, acompanhou os alunos e professoras até o Arroio Pampa, para que cada um deles tirasse uma fotografia desse ambiente, fazendo diferentes registros ${ }^{10}$ da situação do local, onde as casas têm sido invadidas pelas águas do arroio, sendo que uma delas, inclusive, teve sua parede derrubada, e os móveis levados pela água (Figura 3).

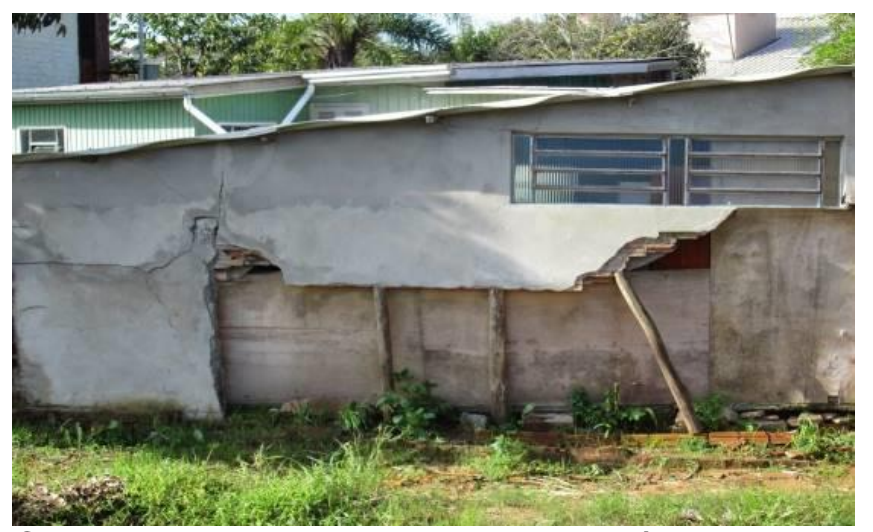

Figura 3: Casa que teve a parede rompida e os móveis levados pela água

Fonte: Alunos participantes do projeto.

\footnotetext{
${ }^{10}$ Para visualizar as diferentes fotos feitas pelos alunos, cf.

http://ecoletivodeodoro.blogspot.com.br/2014/08/fotografia-teoria-e-pratica.html
}

Revbea, São Paulo, V. 11, № 1: 335-354, 2016.

revista brasileira

educação ambiental 
Recebemos, então, jornalistas do Jornal NH (de grande circulação em nosso município), que promovem o Projeto Jornal $\mathrm{NH}$ na sala de aula ${ }^{11}$; eles conversaram com os alunos, fornecendo dicas e informações acerca de como realizar as entrevistas. Nas semanas seguintes, passamos a pensar e a redigir coletivamente o roteiro das entrevistas que faríamos com a comunidade, coma COMUSA, com o COMITESINOS e com a administração municipal. Os alunos foram formulando oralmente as questões que queriam fazer, observando o que aprendemos com as jornalistas. As questões elaboradas foram sendo registradas no quadro para que pudéssemos chegar às perguntas que o grupo queria fazer aos entrevistados escolhidos. Com o roteiro das entrevistas pronto, o próximo passo foi agendá-las com os convidados e selecionar quais alunos fariam as entrevistas.

Durante a realização desse projeto, vez ou outra, saíam reportagens nos jornais e nas emissoras de televisão locais e nacionais, com questões relacionadas aos nossos arroios ou ao nosso Rio dos Sinos, algumas dando ênfase às enchentes. Então, sempre que tínhamos acesso a uma dessas reportagens impressas ou em vídeos, aproveitávamos para ler, ver, analisar, debater em sala de aula e ir a campo, se possível, comparando-as com o que convivíamos em nossa comunidade.

Por iniciativa da professora da turma, que também observou no microscópio diversas amostras de água ${ }^{12}$, agendamos uma visita à COMUSA. Então, entendemos que seria bastante produtivo assistirmos a um vídeo ${ }^{13}$, explicando passo a passo como se dava o tratamento da água numa estação para tal fim, com vistas a uma melhor compreensão da dificuldade de tornar a água dos nossos arroios e rios potáveis. Conversamos a respeito da responsabilidade que toda a sociedade tem, mas alguns setores mais que outros, já que poluem em uma escala maior e de forma mais pesada. E que todos devem ter direito ao acesso à água potável. Então, comparamos o vídeo que assistimos às informações e fotos do site da COMUSA ${ }^{14}$ para verificarmos se o processo de tratamento era o mesmo.

Outra atividade que não estava prevista no Projeto de Ação, mas que é válido o registro, foi a participação desses alunos na $2^{\text {a }}$ Feira Municipal de Iniciação Científica e Tecnológica (FEMICTEC) ${ }^{15}$, promovida pela Secretaria Municipal de Educação (SMED). O evento reuniu pesquisas de alunos desde a Educação Infantil até os anos finais do Ensino Fundamental no Centro de Eventos da FENAC, nos dias 17 e 18 de setembro de 2015. Nesse evento, eles

\footnotetext{
${ }^{11} \mathrm{~A}$ cada semana, o programa Jornal na Sala de Aula viabiliza aos alunos e professores integrantes da iniciativa um exemplar do Jornal $\mathrm{NH}$.

${ }^{12}$ Link das fotos da observação das águas no microscópio:

http://ecoletivodeodoro.blogspot.com.br/2014/08/observacao-da-agua-atraves-do.html

${ }^{13}$ Link do vídeo tratamento de água no nosso blog: http://ecoletivodeodoro.blogspot.com.br/2014/08/ocaminho-das-aguas-1-de-2.html

${ }^{14}$ Link para material da COMUSA no nosso blog:

http://ecoletivodeodoro.blogspot.com.br/2014/08/comusa-tratamento-da-agua.html

${ }^{15}$ Link para visualizar fotos da participação na II FEMICTEC

:http://ecoletivodeodoro.blogspot.com.br/2014/09/ii-femitec.html

Revbea, São Paulo, V. 11, № 1: 335-354, 2016.
} 
demonstraram os estudos que realizaram em sala de aula com a professora titular, relacionados ao tema da água e também relataram as atividades que estavam sendo desenvolvidas, a fim de se fazer um documentário de entrevistas sobre os Arroios Pampa e Peri, no Projeto de Educação Ambiental.

Depois de um período de preparação, os alunos estavam prontos para as entrevistas, que serviram como base para a produção do vídeo. Foram realizadas entrevistas com a comunidade, com a técnica química, profissional responsável pela educação ambiental da COMUSA, e com o presidente do COMITESINOS. Só não se efetivou a entrevista com o prefeito do nosso município, apesar de solicitarmos agendamento mais de uma vez, por telefone e por ocasião da FEMICTEC, onde ele esteve presente.

Realizamos uma pré-estreia do vídeo, em nossa escola, com algumas entrevistas já gravadas, além da leitura da reportagem do Jornal $\mathrm{NH}$, relativa às ações da prefeitura para evitar as enchentes. Após a exibição, seguiu-se uma roda de conversas com a comunidade escolar presente. Por fim, culminamos com a exibição do documentário ${ }^{16}$ na nossa escola, realizada junto à Mostra Multicultural.

\section{A Educomunicação em uma comunidade que convive com as enchentes: resultados}

Iniciar um projeto, proporcionando um momento de conversas dos alunos com profissionais da área da comunicação, a fim de qualificar o trabalho que iria ser realizado por eles, acabou também por motivá-los ainda mais. As saídas a campo proporcionaram um olhar mais atento e observador em relação ao local onde vivem, como, por exemplo, no momento em que ficaram surpresos ao encontrarem fezes saindo do cano, o que foi fotografado por eles. Nesse instante, perceberam o que de fato é um esgoto jogado no arroio e passaram a observara quantidade de canos que apontam diretamente para as águas do arroio e que agora começavam a ser vistos de modo diferente.

Quanto às entrevistas com a comunidade, percebemos respostas, em geral, sucintas. Não sabíamos se era por estarem falando para uma câmera ou por terem medo de falar algo que os comprometesse depois ou, ainda,se realmente era isso que tinham a dizer. Entre os entrevistados, o tema evidenciado foi o fato das águas entrarem em suas casas, o medo que isso gerou e gera por poder voltar a acontecer. O lixo e os entulhos colocados no arroio ou às margens dele foi outro item destacado. Não ficou evidente para eles nem a questão do mau cheiro, nem da poluição das águas pelo esgoto, ou mesmo a responsabilidade das indústrias ou do governo.

\footnotetext{
${ }^{16}$ Link para assistir ao documentário: Vozes dos arroios Pampa e Peri: http://ecoletivodeodoro.blogspot.com.br/search/label/Document\%C3\%A1rio\%20\%20\%20Vozes\%20dos\%2 0arroios\%20Pampa\%20e\%20Peri
} 
$\mathrm{Na}$ entrevista concedida pela profissional responsável pelo setor socioambiental da COMUSA, o fato que chamou a atenção dos alunos foi a descoberta de que o Arroio Pampa e o Rio dos Sinos estão muito próximos de atingirem o nível máximo de poluição, o nível quatro, e de que, na realidade, já não se deveria mais coletar água do rio para consumo; no entanto, é a água que temos disponível. Ainda, a profissional salientou que a COMUSA tem feito um trabalho de EA e de conscientização sobre o lixo colocado no entorno e dentro de arroios e rios. Também foi falado, durante a entrevista, sobre a falta de chuvas e o fato de que poderemos, em breve, passar pela mesma situação que São Paulo está passando e não termos mais água. E como será no futuro se realmente não pudermos mais utilizar suas águas?

Em relação ao esgoto, foi dito que em Novo Hamburgo só 5\% dele está sendo tratado, mas que estão sendo construídas novas estações de tratamento. Assim, a profissional da COMUSA ainda relatou que todos os municípios integrantes da Bacia Hidrográfica do Rio dos Sinos, que totalizam 32 , devem fazer o mesmo para que os arroios e rios não recebam esgoto diretamente em suas águas.

Em sala de aula, ao relembrarmos a possibilidade da falta de abastecimento de água para a nossa cidade, uma aluna disse: "Então, vamos comprar água de garrafinha!' Estava solucionado! A partir disso, levantamos questões diversas: quantas garrafinhas iremos precisar para o consumo diário de uma pessoa? De uma família? De onde virá essa água? Por quanto tempo teremos água disponível desse lugar? Quanto isso vai nos custar? Será que o custo disso vai ser maior ou menor? Será que todos terão condições de comprar água suficiente para suas necessidades? Será que algumas pessoas terão mais dificuldades em comprar do que outras? Ou seja, tentamos ampliar o debate e mostrar que as questões ambientais são muito mais complexas do que parecem à primeira vista e acabam atingindo as pessoas diferentemente, conforme suas condições sociais ou econômicas.

Com a entrevista do presidente do COMITESINOS, ficaram claras a composição, a função de gerenciamento da bacia do Rio dos Sinos, as tensões e os conflitos gerados pelos interesses de cada setor da comunidade, que fazem uso compartilhado de suas águas e pelas quais também são responsáveis, conforme fica bem representado na apresentação digital (Figura 4), elaborada pelo do próprio COMITESINOS ${ }^{17}$ :

${ }^{17}$ Link pra ver fotos de alguns dos slides do COMITESINOS no site da nossa escola: http://ecoletivodeodoro.blogspot.com.br/search?updated-max=2014-10-17T17:54:00-

07:00\&max-results $=7 \&$ start=27\&by-date $=$ false

Revbea, São Paulo, V. 11, № 1: 335-354, 2016. 


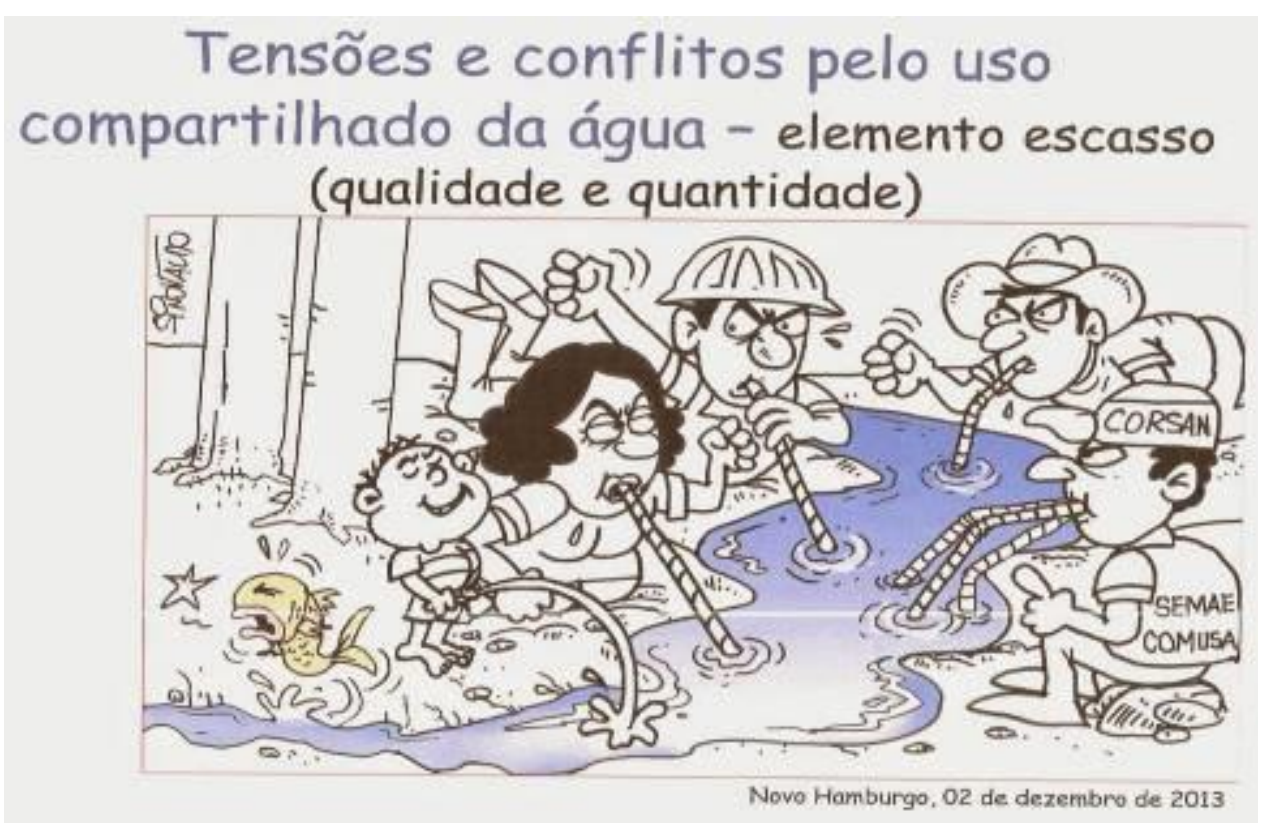

Figura 4: Slide de apresentação referente ao uso da água. Fonte: COMITESINOS.

Foi falado também a respeito do Plano de Bacia do Rio dos Sinos ${ }^{18}$, lançado em 03 de julho de 2014, pelo COMITESINOS, fruto de construção coletiva e da participação social, cujas metas devem ser cumpridas em até vinte anos, entre elas, a prevenção de enchentes, o planejamento de habitação e a qualidade da água. Esse plano deverá ser colocado em ação pelos governos, sociedade privada e sociedade em geral. O presidente do COMITESINOS também contou que brincava nas árvores, nas ruas e no arroio do seu bairro, quando era criança. Os alunos ouviram atentamente a resposta, e foi aí que a aluna L., nove anos, realmente indignada, falou: "Que coisa injusta. Vocês podiam brincar no arroio, nós não!' Ao que prontamente, o entrevistado respondeu: "Você tem toda a razão! É injusto mesmo! Não podem brincar no arroio, nem nas ruas". Noções de justiça ambiental que, aos poucos, vamos adquirindo.

E aqui vale colocar que, em um levantamento feito no primeiro semestre, grande parte dos alunos definiu arroio como sendo um lugar com água suja, para onde vai o esgoto e onde se coloca o lixo. Essa é uma constatação chocante da visão que as crianças têm dos nossos arroios, por ser essa a única realidade que conheceram. Elas ficaram surpresas e maravilhadas quando viram vídeos que mostravam arroios ainda preservados. Imagens que mostravam que os arroios originalmente são cursos naturais de água e parte integrante da natureza. Algumas crianças chegaram a verbalizar não imaginarem que um arroio pudesse ser assim tão lindo!

${ }^{18}$ Links para o COMITESINOS e o plano de bacia:

http://www.comitesinos.com.br/2014/07/806/http://www.comitesinos.com.br/planos-estudos-tecnicos-elegislacao/10-plano-de-bacia/ 
Após a exibição das entrevistas na pré-estreia, houve uma roda de conversas com a comunidade presente, iniciada com a citação de que o Plano de Bacia foi aprovado, o que representa uma conquista para a nossa região, mas que agora restava saber se realmente as ações planejadas serão colocadas em prática pelos setores responsáveis. Também foi falado que, em Novo Hamburgo, havia sido aprovada a lei que prevê multas para quem jogar lixo no chão ${ }^{19}$, como ocorreu em Porto Alegre, o que, na visão da comunidade, é uma lei interessante, mas que a deixava em dúvida quanto à aplicação da mesma. Além disso, foi dito que, com a limpeza e o desassoreamento do Arroio Pampa, realizados pela prefeitura, recentemente, havia melhorado no que se refere à questão dos alagamentos.

Porém, foi lembrado que após essas medidas tomadas pelo município, não havia mais ocorrido chuvas como as do período anterior a elas, tal qual observado pelo Jornal $\mathrm{NH}$, em reportagem do dia 26 de agosto de 2014, que consta no vídeo, e que, dessa forma, não teve o mesmo risco de ocorrer alagamentos e enchentes como no ano anterior. Sendo assim, tínhamos que ter o cuidado para não nos iludirmos e pensarmos que estava tudo resolvido. Os pais concordaram com esse fato, mas um deles lembrou que, antes, com qualquer chuvinha, o arroio transbordava em alguns pontos e que isso não havia acontecido após as recentes limpezas.

Um pai se referiu ao sonho de ver a promessa das redes de esgoto ser cumprida e do sonho de que seus filhos ou netos pudessem voltar a ver um arroio com peixes. Pouco se falou a respeito das responsabilidades de outros setores da sociedade (privado e governo) em relação aos arroios. Também pouco se falou em investimentos urgentes, em prevenção de futuras enchentes, em sistemas de alerta para avisar que a água está subindo, em poluição industrial, em sistema de drenagem da água da chuva, ou em questões sociais que levavam as pessoas a morarem em cima dos arroios. Somente um pai comentou que ninguém morava perto do arroio porque queria e que seria preciso um planejamento de habitação. Reduzir as questões socioambientais aos arroios assoreados, com o esgoto doméstico que cai direto em suas águas, à questão do lixo doméstico colocado pela comunidade, que sofre diretamente com 0 arroio poluído, demonstra que a mídia tem propagado muito bem o discurso em que todos aparecem como culpados pelos "problemas" ambientais, enquanto atribui-se a cada um a solução ${ }^{20}$.

Por fim, culminamos com a apresentação do documentário ${ }^{21}$ na nossa escola, que ocorreu junto a Mostra Multicultural. Nesse dia, não finalizamos a

\footnotetext{
19Link lei do lixo no chão: http://www.jornalnh.com.br/ conteudo/2014/08/noticias/regiao/78386em-novo-hamburgo-quem-jogar-lixo-na-rua-agora-vai-pagar-multa.html.

${ }^{20}$ Refletindo o que Santos et al. (2013) chamam de EA de Etiqueta, Autoajuda e Perfumaria, focada apenas na mudança individual de postura sem uma crítica envolvendo a realidade societária.

${ }^{21}$ Link para assistir ao documentário: Vozes dos arroios Pampa e Peri: http://ecoletivodeodoro.blogspot.com.br/search/label/Document\%C3\%A1rio\%20\%20\%20Vozes \%20dos\%20arroios\%20Pampa\%20e\%20Peri

Revbea, São Paulo, V. 11, № 1: 335-354, 2016.
} 
exibição e nem houve debate, devido ao temporal que se armou, fazendo com que a comunidade quisesse voltar logo para suas casas. Conforme colocou uma mãe, "qualquer chuvinha a gente quer estar em casa para cuidar e ver o que vai acontecer". A mesma preocupação também é manifestada por alguns alunos que, em dias de aula, demonstram seu medo assim que a chuva começa a se intensificar, sendo que até chegam a chorar ao verem a chuva pela janela da sala de aula, necessitando serem confortados pela professora. ${ }^{22}$

Com a finalização desse projeto, concluímos o quão complexas são as questões pertinentes aos nossos arroios e, por fim, ao gerenciamento da água da nossa bacia hidrográfica, cujo uso é compartilhado por diversos setores da sociedade, setores que têm muitos interesses diferentes envolvidos e, por isso, se tornam conflitantes. Há questões que precisam de atenção e ação urgentes, pois têm causado apreensão, medo e perdas, como no caso das inundações. Temos em mãos um Plano de Bacia, conquistado pela dedicação e esforço, ao longo de muitos anos de trabalho por parte do COMITESINOS e que, se colocado em prática, conforme planejado, por etapas, a expectativa é de que, no final de vinte anos, teremos outra realidade, que implica a melhoria da qualidade das águas da Bacia Hidrográfica do Rio dos Sinos e da qualidade da vida das pessoas, pois além da recuperação do rio, as questões das enchentes também estão contempladas nesse plano. Cabe a participação do povo também nesse processo de acompanhar e cobrar a efetivação do plano por todos os setores da sociedade: civil, setor privado e governo.

Seremos eternos professores aprendentes (COUSIN, 2010) quando fazemos a opção por uma Educação Ambiental "vista como um processo de permanente aprendizagem, que valoriza as diversas formas de conhecimento e forma cidadão com consciência local e planetária" (JACOBI, 2003, p. 6). E é nesse viés que cidadãos atuantes têm encontrado alternativas de ações de transformação social. É com "[...]estratégias argumentativas e formas de luta inovadoras que os atores sociais [...] têm procurado fazer do ambiente um espaço de construção de justiça e não apenas de realização da razão utilitária do mercado" (ACSELRAD, 2005, p. 228).

Esse projeto possibilitou aos alunos protagonizarem atividades que envolveram o diálogo com a comunidade, conversando com os diferentes atores sociais (com exceção do atual administrador do município) e, por conseguinte, com saberes diferentes, reconhecendo, assim, a complexidade da situação, as atuações e responsabilidades de cada setor, além da inserção de questões e noções de justiça ambiental. Assim, acreditamos que a utilização da Educomunicação socioambiental como um instrumento pedagógico é de grande valia para alcançar objetivos da Educação Ambiental que se propõe transformadora.

${ }^{22} \mathrm{O}$ medo da chuva é uma questão que aparece em outras realidades, como citado por Santos (2010)edisponível em: http://www.tede.udesc.br/tde_busca/arquivo.php?codArquivo=2305.

revista brasileira educação ambiental 


\section{Para refletir e caminhar: considerações finais}

Percebemos que a Educomunicação pode ser incentivada como uma proposta pedagógica para a Educação Ambiental ampliando o debate e fazendo frente a uma mídia que carrega em si um discurso, dito neutro, de uma sustentabilidade que acaba por sustentar um sistema desencadeador de uma crise civilizatória com graves consequências ambientais e sociais.

Sabemos que é um imenso desafio, que temos muitos limites para superar, mas que desponta também como possibilidade de democratização e acessibilidade a quem não tem vez nem voz. A comunidade se viu representada nesse documentário, uma vez que a escola ganhou as ruas e adentrou as portas dos moradores, que se abriam para compartilhar as suas vivências. Suas falas ficaram registradas e sempre poderão ser acessadas para serem ouvidas ou servirem de chamado à participação da comunidade em busca de uma justiça que não a exclua de seus direitos e de sua cidadania.

Os alunos foram agentes ativos da sua aprendizagem, produzindo, compartilhando, analisando e debatendo a respeito dos diferentes saberes durante a produção desse documentário. Foram, a todo o momento, instigados a ampliar sua observação, a analisar criticamente a realidade, a questionar 0 que leem, o que veem, o que ouvem. Tiveram a oportunidade de ouvir, de diferentes atores sociais, acerca de suas responsabilidades e ações, entendendo a complexidade das questões ambientais e o fato de que as causas e as consequências vão além de cada cidadão fazer a sua parte.

Também foram apresentadas as noções de justiça ambiental, o que de fato é um tema ainda muito novo para eles. Como educadores ambientais que almejamos ser, críticos, inseridos e transformadores de uma realidade, precisamos ter coragem de ampliar sobre as questões socioambientais e saber que convivemos com injustiças ambientais e que as questões ambientais atingem de forma desigual os diversos setores da sociedade e que os menos favorecidos sofrem um impacto ambiental negativo maior, justamente por terem menos poder social, econômico e político. Tudo isso constitui um aprendizado e um exercício de cidadania.

Em sala de aula, ampliamos o debate referente ao papel e à responsabilidade do governo e da indústria, para que as crianças começassem a observar que tudo é mais amplo e mais complexo e que interfere diretamente na vida das pessoas. Quando assistíamos aos vídeos ou líamos reportagens, também eram levantadas questões que não estavam referenciadas nas notícias, para que elas já pudessem ter a noção de que as notícias veiculadas não contemplam todos os dados e nem todos os envolvidos com as situações descritas e que é nosso papel ir além, saber mais, pesquisar, conhecer, a fim de chegarmos mais próximos da realidade.

A produção de um documentário que envolvesse os nossos alunos como autores, produtores, e que saísse dos muros da nossa escola para retratar tal realidade, convidando a comunidade a participar, com seus saberes e suas impressões, tornou o nosso estudo bastante rico. As crianças estavam 
motivadas a participar. Quem já havia entrevistado, queria entrevistar novamente e quem ainda não tinha feito, aguardava ansiosamente sua vez. Após as entrevistas, vídeos e leituras de jornais, fazíamos reflexões, questionamentos e debates. Houve falas e pontuações de alunos que nos fizeram parar para refletir, pela autenticidade que só as crianças têm e que representaram pontos de partida para debates posteriores. Essas ponderações só são possíveis quando oportunizamos espaço para tal.

Sabemos que a ação relatada neste artigo tem muitos limites e possibilidades, como todas as ações que realizamos. Portanto, ela deve ser avaliada criticamente para que novas propostas que envolvam o uso de mídias possam ocorrer e venham a ser aprimoradas a fim de que consigamos atingir novos objetivos. Dessa forma, acreditamos que a Educomunicação feita pela comunidade e para a comunidade possa ser um elo entre a mesma e a escola, e assim servir como canal de diálogo, ampliando as reflexões referentes às questões ambientais e possibilitando a percepção de questões muito mais abrangentes do que apenas ações individuais tão propagandeadas pela mídia através do receituário de que cada um pode salvar o planeta (SANTOS et al., 2013). É urgente e necessário trazer à tona as questões políticas, econômicas e sociais para os debates existentes, já que estão todas interligadas. É um imenso desafio que deve ser aceito para que uma proposta de Educação Ambiental se configure como transformadora.

\section{Agradecimentos}

A Prefeitura Municipal de Novo Hamburgo, SMED (Secretaria Municipal de Educação), Coletivo Educador Educação Ambiental e, em especial, a gerente de Educação Ambiental por oportunizarem e incentivarem a formação continuada indispensável aos educadores. A Universidade Federal do Rio Grande e Universidade Aberta do Brasil - UAB (Polo Sapiranga) por possibilitarem o acesso ao Curso de Especialização em Educação Ambiental. Aos alunos, comunidade, colegas e equipe diretiva da Escola EMEF Presidente Deodoro da Fonseca de Novo Hamburgo por apoiarem e participarem da realização do Projeto de Ação concretizado neste espaço. E a Fundação de Amparo à Pesquisa do Estado do Rio Grande do Sul - FAPERGS e CAPES pela bolsa de Doutorado do segundo autor.

\section{Referências}

ACSELRAD, H.; MELO, C.C.; BEZERRA, G.N. O que é justiça ambiental. Rio de Janeiro: Garamond, 2009.

ACSELRAD, H. Justiça Ambiental. In: Encontros e caminhos: formação de educadoras(es) ambientais e coletivos educadores. 2005. p. 217 - 228. Disponível $<$ http://www.mma.gov.br/estruturas/educamb/ arquivos/encontros.pdf>. Acesso em: 10 de maio de 2014 às 18:44

revista brasileira educação ambiental 
ARAÚJO, C. Educação Ambiental e Mídia: a construção de um discurso. 2013. Disponível em arquivo eletrônico para o Curso de Especialização em Educação Ambiental (UAB/FURG).

BRASIL. Lei no 9.795, de 27 de abril de 1995, institui a Política Nacional de Educação Ambiental. Diário Oficial da República Federativa do Brasil. Brasília, 28 de abril de 1999.

BRASIL. Diretrizes Curriculares Nacionais para a Educação Ambiental. Diário Oficial da União. Brasília, no 116, 2012.

CONFERÊNCIA MUNICIPAL DE EDUCAÇÃO. 1, 2012, Novo Hamburgo: documento de trabalho. Novo Hamburgo, 2012. Disponível em: $<$ http://educacao.novohamburgo.rs.gov.br/modules/conteudo/conferenciaed. php?conteudo=15>. Acesso em: 16 jan. 2013às 13:03.

CONFERÊNCIA MUNICIPAL DE EDUCAÇÃO. 1, 2012, documento final. Novo Hamburgo, 2012. Disponível em: $<$ http://educacao.novohamburgo.rs.gov.br/uploads/parent folder/fcbcdaefdbbf4 32564400/cceedbcbedaaf1262701155/bddbaacf872261693.pdf>. Acesso em: 16 jan. 2013 às 15:30.

COSTA, F.A.M.. Educomunicação socioambiental: comunicação popular e educação.Brasília: MMA, 2008. Brasil. Ministério do Meio Ambiente. Secretaria de Articulação Institucional e Cidadania. Disponível em: http://www.mma.gov.br/estruturas/educamb/ arquivos/txbase educom 20.pdf. Acesso em: 17 de jul. 2014 às 21:47.

COUSIN, C.S. Pertencer ao navegar, agir e narrar: a formação de educadores ambientais. 2010. 207 f. Tese (Doutorado) - Programa de Pós-Graduação em Educação Ambiental, Universidade Federal do Rio Grande, Rio Grande, 2010. Disponível em: http://www.argo.furg.br/bdtd/tde arquivos/5/TDE-2010-1222T103804Z-254/Publico/Claudia.pdf. Acesso em: 30 de abr. 2014 às 19:16.

FREIRE, P.; SHOR, I. Medo e ousadia: o cotidiano do professor. Rio de Janeiro: Paz e Terra, 1986.

JACOBI, P. Educação ambiental, cidadania e sustentabilidade. Cad. Pesquisa São Paulo, n. 118, mar. 2003. Disponível em $<$ http://www.scielo.br/scielo.php?script=sci arttext\&pid=S0100-

15742003000100008\&lng=pt\&nrm=iso $>$. Acesso em: 30 de abr. 2014 às 21:24.

LOUREIRO, C.F.B. Emancipação. In: FERRARO JÚNIOR, L.A. Encontros e Caminhos: Formação de Educadoras(es) Ambientais e Coletivos EducadoresVolume 2. Brasília: MMA, Diretoria de Educação Ambiental, 2007. p. 157-170. Disponível em: $<$ http://www.mma.gov.br/estruturas/educamb/ arquivos/encontros 2.pdf>.

Acesso em: 16 de mai.2014 às 18:33.

LOUREIRO, C.F.B. Trajetória e fundamentos da educação ambiental. São Paulo: Cortez, 2004. 
SANTOS, C.F. et al. (Orgs.) Conflitos no centro da Educação Ambiental. In: MACHADO, C. et al. Conflitos ambientais e urbanos: debates, lutas e desafios. Porto Alegre: Evangraf, 2013. p.217 - 243.

SANTOS, C.F. A enchente em Itajaí (SC): relatos, percepções e memórias. Dissertação (Mestrado em Planejamento Territorial e Desenvolvimento Socioambiental)2010. 107 f. UDESC. Florianópolis, 2010. Disponível em: $<$ http://www.tede.udesc.br/tde busca/arquivo.php?codArquivo=2305 $>$. Acesso em: 21 de jul. de 2014 às 20:22.

SANTOS, C.F.; TORNQUIST, C.S.; MARIMON, M.P.C. Indústria das enchentes: impasses e desafios dos desastres sócio-ambientaisno vale do Itajaí. GEOSUL. Florianópolis. v. 29, n. 57 2014. Disponível em: $<$ https://periodicos.ufsc.br/index.php/geosul/article/view/21775230.2014v29n57p197>. Acesso em: 16 de out.de 2014 às 23:00.

SGARBI, K. As ações das prefeituras contra enchentes. JORNAL NH, Novo Hamburgo, 26 ago. 2014, p.10.

THIELE, P.R. Análise das políticas ambientais aplicadas aos moradores das margens do Arroio Pampa no município de Novo Hamburgo. Dissertação (Mestrado em Geografia), 129 f. UFRGS. Porto Alegre. 2004. Disponível em: $<$ http://hdl.handle.net/10183/6143>. Acesso em: 14/09/2015.

TRAJBER, R. Educomunicação para coletivos educadores. Encontros e caminhos: formação de educadoras (ES) ambientais e coletivos educadores. In: FERRARO JÚNIOR, L.A. (Org.). Brasília: MMA, Diretoria de Educação Ambiental, 2005.2 Disponível em: $<$ http://www.mma.gov.br/port/sdi/ea/og/pog/arqs/encontros.pdf $>$. Acesso em: 17 de jul. de 2014 às 18:27. 